\title{
Science Council of Japan (SCJ)
}

\section{Statement: Code of Conduct for Scientists}

(Approved at the general meeting of the Science Council of Japan on Oct. 3, 2006, and translated from the original Japanese version ${ }^{1}$ )

\section{Overview}

The Science Council of Japan has conducted extensive reviews of misconduct in all areas of academic activity, including humanities, social sciences and natural sciences, during its 18th and 19th terms through its Standing Committee on Science and Society. The Committee published reports during each of these two terms ("Misconduct in science and its prevention" and "The current state of misconduct and measures to combat it: Toward an autonomous community of scientists", respectively). The Council also exerted continuous efforts to prevent misconduct in science through various other activities. These included distributing a public information pamphlet ("Scientific Misconduct and its Prevention"2) and holding public lectures on the topic.

Science involves intellectual activities that are indispensable to human beings, and its products are intellectual property that is shared by all human beings. Scientists, as members of the scientific community who are responsible for the healthy development of science, are thus required to maintain strict control of their own activities. We consider the recent spate of misconduct by scientists taking place in Japan and elsewhere to be serious threats to the integrity of science. Even misconduct by one scientist can compromise public trust in the scientific community at large, as well as the intellectual activities of science in general. Scientists in Japan are recently witnessing drastic changes in their research environment, with more intense competition for research funding and an increase in non-tenured employment, culminating in stronger pressure to produce research results quickly. Facing such a situation, scientists' autonomy and integrity are now at stake. The Science Council of Japan, representing the scientific community in Japan, recognizes the need to regain the trust of society in science, which is indispensable for achieving the mission of science. It also recognizes that, in order to regain this trust, we are required to raise the self-awareness of all scientists, as well as encouraging relevant institutions and organizations to establish means whereby misconduct may be prevented. 
In view of this, the Science Council of Japan established a Committee on the Code of Conduct for Scientists in October 2005, starting an intensive review of scientists' duties and powers as well as ways for the scientific community to deal with ethical issues. The Committee drafted a preliminary version of the Code of Conduct for Scientists and an accompanying document entitled "Improving Self-Discipline by Scientists," both of which were approved by the General Meeting of the Council in April 2006. The Council then distributed the Code and accompanying document, together with a questionnaire, to 1,251 universities and colleges, 272 research institutes, and 1,296 academic associations that have a collaborative relationship with the Council. The questionnaire solicited views and opinions about the preliminary version of the Code, and asked institutions about their own progress on establishing ethical codes and codes of conduct.

The committee received 1,332 informative responses to the questionnaire from various institutions and associations. Most of them expressed a favorable reaction to the preliminary version of the Code. Some affirmed that all the necessary requirements were listed in the Code, while others posed the criticism that the Code was too abstract and lacked explicit guidelines for conduct. Some also pointed out that topics specific to their discipline were missing. Questions about ethical codes and codes of conduct established by the institutions received 1,323 responses, indicating those institutions' activities aimed at establishing such codes (or lack thereof).

The Committee on the Code of Conduct for Scientists continued its review based on careful examination of the results of this questionnaire, made appropriate additions and revisions, and finalized the "Code of Conduct for Scientists" that constitutes the core of this Statement. The Committee changed the title of the accompanying document, ("Improving Self-Discipline by Scientists") to "Toward Autonomous Implementation of the Code of Conduct for Scientists." The purpose of the revision was to make it clear that the accompanying document is meant to supplement the Code and that the two together constitute a single statement.

The Code of Conduct presented in this Statement delineates a basic code of conduct for scientists in all academic disciplines, helping them to gain the trust of society and to autonomously pursue scientific research activities, thereby leading to the healthy development of science. This general nature of the Code precludes it from enumerating specific guidelines for conduct required in particular areas of academic activity. The Science Council of Japan requests each university, college, research institution, and academic association to establish its own code of conduct that meets the unique requirements and demands of its own discipline, by referring to the Code and reflecting the spirit of the articles specified in it. The Council 
further requests each institution and association to enforce the demands specified in the accompanying document ("Toward Autonomous Implementation of the Code of Conduct for Scientists") by establishing its own program of ethics. Specifically, the Council requests that each institution and association exerts continuous efforts to promote education on research ethics and foster healthy research environments including relations among researchers, and to establish and effectively implement strict and impartial measures to deal with misconduct.

The Science Council of Japan is determined to continue its efforts to promote the development of academic activities and to foster healthy relationships between society and the scientific community. For this purpose, the Council will pursue continued communication with society as well as with the individual scientists, educational and research institutions, and academic associations that together constitute the scientific community. The Council hopes that the wisdom and efforts of all scientists in Japan will be applied to this endeavor.

1 Original Document (Japanese)

http://www.scj.go.jp/ja/info/kohyo/pdf/kohyo-20-s3.pdf

2 "Scientific Misconduct and its Prevention" (Science Council of Japan, May 2005): http://www.scj.go.jp/ja/ print/pdf/taigai_reefe.pdf 


\section{Code of Conduct for Scientists}

Science is a system of knowledge based on the principles of reason and empirical proof that is assiduously built up over time, and constitutes an irreplaceable common asset of all humanity. Scientific research is an act that creates new knowledge by boldly pursuing the challenges of unknown fields.

Science and scientific research exist both with and for society. Therefore, research activities based on scientific freedom and the subjective judgment of scientists only gain social recognition once they are premised upon public trust and the mandate of the people. Here, the word "scientists" refers to researchers and specialists engaged in activities that create new knowledge, or in the use and application of scientific knowledge, in all academic fields ranging from humanities and social sciences to natural sciences, regardless of which institution they belong to.

While scientists engaged in such intellectual activities enjoy the prerogative to pursue truth under academic freedom based on their own expert judgments, as experts they also bear a grave responsibility to respond to the mandate given to them by society at large. Especially in the modern world, where scientific activities and their results exert a vast and profound influence on all humanity, society demands that scientists always make ethical judgments and engage in ethical actions. Thus, for science to contribute to realizing a more affluent human society through its own sound growth and development, scientists must establish ethical norms to strictly control their own conduct, while fulfilling their obligation of accountability to society and consciously taking part in building and maintaining sound relationships between science and society. Ethics for scientists also constitute a basic framework whereby society can demonstrate its understanding of science and seek dialog with science.

Based on the fundamental recognition described above, the Science Council of Japan has formulated a Code of Conduct consisting of ethical principles that should originate in the autonomy of scientists and are minimum requirements common to all academic fields. Adherence to such ethical principles is essential, both to ensure the quality of scientific knowledge and for individual scientists and the scientific community to gain the trust and respect of society at large.

\section{Responsibilities of Scientists}

Scientists shall recognize that they are responsible for assuring the quality of the specialized knowledge and skills that they themselves create, and for using their expert knowledge, skills and experience to contribute to the health and welfare of humankind, the safety and security of society and the sustainability of the global environment. 


\section{Conduct of Scientists}

Scientists shall recognize that scientific autonomy is upheld by public trust and the mandate of the people, and shall always make judgments and act with honesty and integrity. Moreover, scientists shall make the utmost effort to scientifically and objectively demonstrate the accuracy and validity of the knowledge they create through scientific research, and shall actively participate in mutual quality assurance such as peer reviews in the scientific community, especially in their respective fields of expertise.

\section{Continuous Professional Development}

As well as endeavoring to maintain and improve their own expertise, abilities and skills, scientists shall constantly strive to understand the relationships between science, technology, society and the natural environment from a wide-ranging perspective, and to demonstrate the best judgments and attitudes at all times.

\section{Accountability and Disclosure}

Scientists shall strive to disclose and actively explain the roles and significance of their own research, evaluate the possible effects of their research on people, society and the environment as well as the changes that their research might engender, neutrally and objectively disclose the results of this evaluation, and build a constructive dialog with society.

\section{Research Activities}

Scientists shall act with integrity according to the spirit of this Code of Conduct in drafting, planning, applying for, implementing and reporting their own research, ensure that research and survey data are recorded, stored and rigorously handled, and not only refrain themselves from any misconduct such as fabrication, falsification or plagiarism, but also refrain from aiding or abetting such misconduct.

\section{Establishing Sound Research Environments}

Scientists shall recognize that establishing and maintaining fair research environments where responsible research can be conducted is one of their important duties, and shall actively participate in efforts to improve the quality of research environments in the scientific community and their own institutions. Moreover, they shall also seek the understanding and cooperation of the public in achieving these goals.

\section{Compliance with Laws and Regulations}

Scientists shall observe all laws, regulations and relevant rules in their activities, including the implementation of research and the use of research funds. 


\section{Consideration for Research Subjects.}

Scientists shall respect the dignity and rights of individuals who cooperate with their research, and shall safeguard and give proper consideration to their welfare. They shall also treat animals and other research subjects with all due care and respect.

\section{Relations with Others}

Scientists shall constructively criticize the results of other scientists' research, humbly listen to the criticism of others, and exchange opinions with an attitude of sincerity. Moreover, they shall properly give credit to other scientists' intellectual findings and achievements, as well as respecting the honor and intellectual property rights of others.

\section{Rejection of Discrimination}

In their research, education and academic society activities, scientists shall respond to others fairly on a scientific basis, respect individual freedom and character, and not discriminate against individuals based on their race, gender, status, beliefs or religion.

\section{Avoiding Conflicts of Interest}

In their research, reviews, evaluations, judgments and other scientific activities, scientists shall pay sufficient heed to the presence of conflicts of interest between individuals and organizations, or between different organizations, and shall properly address problems paying all due attention to the public interest. 


\section{Toward Autonomous Implementation of the Code of Conduct for Scientists}

The Science Council of Japan herewith requests that each university, college, research institution, academic association and funding agency independently implements a specific program on research ethics (i.e. formulates and applies a code of ethics and a code of conduct) at the earliest possible date. The objectives of this request are to promote the well-balanced development of science with the help of the independent scientific community, and to promote the independent and honest conduct of scientists in light of the aims and needs of their respective organizations.

The following are examples of specific efforts requested herewith. The gist of "The Code of Conduct of Scientists" may also be consulted for reference.

\section{The Responsibility of Organizational Managers}

1. A code of ethics and code of conduct, including the gist of "The Code of Conduct of Scientists", should be formulated and circulated among all members of the organization to ensure their compliance.

2. Those responsible for the management of the organization should lead the program on research ethics and lay down necessary measures to be taken in the event of scientific misconduct. In each organization, they should arrange for their own system of response to research ethics, including permanent special committees, divisions, and persons in charge.

\section{The Need for Education on Research Ethics}

3. In each organization, the code of conduct essential to research activities, such as the prohibition of misconduct and the recording, storage and rigorous handling of research data, as well as research ethics that properly maintain the relationship between research activities and society, should be continuously imparted to members through education, training and information activities. In particular, young scientists should have the opportunity to study past cases of misconduct and thereby learn the critical importance of research ethics.

\section{Important Points for Research Groups}

4. Research groups in each organization should create a research environment suitable for frank exchanges of opinions on research ethics and for the daily operation of peer reviews. For that purpose, these groups should continuously strive to secure freedom, impartiality, transparency, and openness both in terms of their management and the human relationships within the groups. Every member of the group should share the awareness of group objectives to the effect that, through their engagement in scientific research, they are participating in a 
precious intellectual endeavor in the public sphere.

\section{Important Points for Research Processes}

5. Scientists should be reminded of the need to observe the Code of Conduct and act in good faith in all processes such as proposing, planning, applying for and implementing research, as well as reporting the results thereof.

\section{Dealing with Misconduct in Research}

6. To deal with possible misconduct such as fabrication, falsification or plagiarism, the following measures should be taken at the earliest possible date:

(1) A proper channel should be set up for consultation on suspected misconduct. At the same time, particular attention should be paid to the importance of ascertaining whether the suspicion is false.

(2) All due consideration should be made to ensure that anyone reporting misconduct should not suffer disadvantage as a result thereof.

(3) When there is suspicion of misconduct, relevant facts should be promptly investigated in accordance with due procedures, necessary measures should be taken with impartiality, and the result should be made public. Particularly strict measures should be taken in the case of fabrication, falsification or plagiarism.

7. Everyone in the organization should be reminded of relevant laws, ordinances and regulations in carrying out research and using research funds. Due consideration should be given to prevent research activity from becoming unduly constricted, while appropriate rules should be worked out to deal with conflicts of interests.

\section{Establishing a Self-monitoring System}

8. The program on research ethics should be continuously assessed and improved through a system of self-monitoring and self-audit. 